\title{
A Rapid Replacement of Vimentin-Containing Radial Glia by Glial Fibrillary Acidic Protein-Containing Astrocytes in Transplanted Telencephalon
}

\author{
Andrea Tuba, Lázló Kállai and Mihály Kálmán \\ Department of Anatomy, Histology, and Embryology, Semmelweis University of Medicine, \\ Budapest, Hungary, H-1450
}

\section{SUMMARY}

The present study follows the early events in the development of astroglia in rat embryonic (E15) tissue grafted into the cortex of adult rats. Astroglial elements (radial glia and astrocytes) were studied by glial fibrillary acidic protein (GFAP) and vimentin immunohistochemistry on post-transplantation (PT) days 7, 11, 14, 17, and 21. At PT7, GFAP-immunopositive elements were only scarce fibers in the transplants. At PT11, a dense network of long, GFAPimmunopositive fibers enmeshed the entire transplant, and astrocytes were already recognized. The fibers also showed vimentin immunoreactivity. By PT14, astrocytes became the predominant GFAP-labeled elements, although a few long fibers persisted. When compared with in situ development, the grafts showed earlier GFAP-immunoreactivity and earlier appearance of astrocytes, as well as a more rapid transition from the immature to the mature form of the glial system.

\section{KEY WORDS}

neurotransplantation, neurohistogenesis, astroglial development, immunohistochemistry, glial reaction, GFAP, rat embryo

\footnotetext{
Reprint address:

Mihály Kálmán

Department of Anatomy, Histology, and Embryology,

Semmelweis University of Medicine

Tüzoltó 58, Budapest, Hungary, H-1450.

Fax: +36-1-215-5158
}

\section{INTRODUCTION}

Neural transplantation is not only a promising clinical method $/ 8,29 /$ but also a powerful tool for studying neurohistogenesis. As clinical results can be expected only in cases of long-surviving transplants, most data (reviewed in $/ 14,25 /$ ) have been published on transplants that had survived at least for one month or longer. Early post-operative events, however, are crucial for the survival of the transplant, and during this period the transplant can used as a model system for certain neurohistogenetic processes. Experimental evidence has suggested that after a successful transplantation, cell maturation follows a schedule that is similar to that found in situ 19,20,25/. The data from such studies correlate with other observations concerning in vitro development $/ 1,43 /$.

The development and fate of transplanted glia are of interest because grafted immature astroglia can diminish post-lesional neurodegenerative processes /13,32,38,39/ and support axonal regrowth, whereas transplanted oligodendroglial cells are capable of remyelinization /13/. Although several groups have demonstrated the presence of astrocytes in transplants $19,10-12,16,23,37 /$, the first days of astroglial development after transplantation have not yet been adequately investigated.

The decisive stage of astroglial development in situ is the transition from the immature and vimentin-containing radial glia to the mature and glial fibrillary acidic protein (GFAP)-containing astrocytes (reviewed in $/ 24,41 /$ ). The radial glia consists of straight fibers stretching between the ventricular and pial surfaces of the central nervous tissue. This system has an important role in guiding the migrating neuroblasts in the developing brain 
(reviewed in $/ 35 /$ ). After the migration period, however, radial glia in mammals transforms into astrocytes and disappears $/ 28,436,42 /$. GFAP $/ 21 /$ is the characteristic cytoskeletal protein of mature astrocytes (reviewed in $/ 6 /$ ), whereas vimentin, originally described in fibroblasts, is characteristic for immature glia in mammals $/ 18 /$ and almost completely disappears during glial maturation $/ 17,30,34 /$. It should be noted that this description is only correct for mammals. Concerning other vertebrates, the reader is referred to other reports $12,26,33,44 /$, among others. In primates, the transition described above occurs during the fetal period, with the replacement of vimentin by GFAP preceding the transition of the radial glial system into the definitive astrocytes $13,15,28,30,36 /$. In rodents and carnivora, however, which litter rather immature offspring, the aforementioned processes are concurrent in early postnatal life $/ 7,17,22$, $31,34,40,42$ ), thus in such animals only a few or no radial fibers contain GFAP.

Central nervous tissue has transplantation capability only during the early stage of development. In the present study, we followed astroglial development in fetal rat cortical transplants during the post-operative days 7 and 21 . The grafts were transplanted on the 15th embryonic day (E15), which is the lower limit of the time window /25/37/ during which the cortical tissue is in an optimal stage for transplantation. Such a schedule allowed the immature tissue to develop in the alien environment for as long as possible. At E15, the rat brain consists of radial glia and glioand neuroblasts; vimentin is the glial cytoskeletal protein $/ 18,24,25,37 /$. Rat brains developing in situ were removed at different postnatal days corresponding to the equivalent post-transplantation days and fixed and processed in the same way as the transplants. The in situ developmental period involved the peak of transition from radial glia into astrocytes. Our results suggest that the transition of radial glia into astrocytes occurs sooner and more rapidly in the transplanted cortex that it does in situ.

\section{METHODS}

To obtain dated embryos, we prepared vaginal smears from female albino CFY (Carworth Farm Y,
Gödölló, Hungary) rats that had mated with male rats overnight. The day of sperm-positivity was considered as E0. At E15, the embryos were removed from the mother in deep ketamine-xylazine narcosis $(20$ and $80 \mathrm{mg} / \mathrm{kg}$ body weight, respectively, and samples of their neopallium were immediately dissected out. Adult recipient rats (CFY strain) were anesthetized as described above. A piece $(\sim 3 \times 3 \mathrm{~mm})$ of the left parietal bone was removed from each recipient, the dura was pierced, and a pit was formed in the cortical tissue (under gentle suction using a water-jet pump). The embryonic tissue sample was placed in the pit using a pair of microsurgical forceps, the piece of skull bone that had been removed was then repositioned, and the scalp wound was accurately sutured. The recipient rats received antibiotics both locally and systemically.

At post-transplantation periods of $7,11,14,17$, or 21 days (denoted PT7, PT11, etc.), the recipients were anesthetized with an overdose of diethylether and were transfused transcardially with $0.9 \%$ sodium chloride followed by $4 \%$ para-formaldehyde dissolved in $0.1 \mathrm{M}$ phosphate buffer $(\mathrm{pH}$ 7.4). Brains were removed and postfixed overnight in the same fixative used for perfusion. The transplants and the surrounding host tissue were dissected out and embedded in agarose. Serial sections were cut using, a Vibratome and washed overnight in phosphate buffer. Parallel sections were processed for either GFAP or vimentin immunohistochemistry.

Before each reagent change, the sections were rinsed with phosphate buffer at $\mathrm{pH}$ 7.4. To suppress background staining, the sections were first pretreated for $5 \mathrm{~min}$ with $3 \%$ hydrogen peroxide and incubated in non-immune serum (phosphate buffer containing $20 \%$ normal goat serum) for 90 $\mathrm{min}$ at room temperature. The sections were then incubated for $40 \mathrm{hr}$ at $4^{\circ} \mathrm{C}$ with mouse monoclonal antibody to either GFAP or vimentin (clone V9) (Boehringer, Mannheim, Germany), diluted to a final working concentration of $1: 100(200 \mathrm{ng} / \mathrm{ml})$ in phosphate buffer containing $0.5 \%$ Triton X-100. After washing, sections were reacted with biotinylated rabbit anti-mouse immunoglubulin (Amersham) and then incubated with streptavidinbiotinylated horseradish peroxidase complex (Amersham). Each reagent was diluted to a final working concentration of $1: 100$ in phosphate buffer 
and incubated with the sections for $90 \mathrm{~min}$ at room temperature. Immunocomplexes were visualized by the peroxidase reaction: Sections were incubated for $10 \mathrm{~min}$ at room temperature in 3-3'diaminobenzidine $(0.05 \%$ in $0.05 \mathrm{M}$ Tris- $\mathrm{HCl}$ buffer containing $0.01 \%$ hydrogen peroxide, $\mathrm{pH} 7.4$ ). A diaminobenzidine deposit was not seen when the primary antibody was omitted from the procedure.

To form a series of in situ-developing control tissues, we removed the brains of developing rats at postnatal days P0, P4, P7, P10, and P14 and from the donor rats at E15, corresponding to the respective post-transplant days PT7, PT11, PT14, PT17, and PT21 (considering that the gestation period in rats is 22 days). The control brains were fixed, cut into serial coronal sections, and processed in the same way as the transplants.

\section{RESULTS}

\section{In situ cortical astrogliogenesis}

In the E15 donor brain, only vimentinimmunopositive radial fibers were seen; no radial fiber stained positively for GFAP. The same glial pattern was predominant in the in-situ developing cortex from P0-P7. Astrocytes were not found in either the vimentin- or GFAP-immunopositive sections. It should be noted that in other parts of the brain (corpus callosum, internal capsule, and anterior commissure), GFAP-immunopositive astrocytes were already recognizable during the first postnatal week, indicating that the GFAP immunostaining technique was effective.

We detected the first scarce GFAPimmunopositive elements, both radial fibers and astrocytes, at P10 in our material from the cortex developing in situ. Until P14, the number of GFAPpositive astrocytes increased, whereas the number of vimentin-positive radial fibers gradually decreased. The GFAP-immunopositive radial fibers remained scarce, and vimentin-positive astrocytes appeared only exceptionally. As such phenomena have been described before $/ 17,31,34,40 /$, Fig. 1 shows only one characteristic view of an in situ cortex stained for GFAP immunoreactivity at P10, for comparison with the glial structure of the transplants.

\section{Astrogliogenesis in cortical transplants}

In transplants processed at PT7, GFAPimmunoreactive elements were represented by only a few fibers, which were seen predominantly at the vessels in the periphery of the transplant (Fig. 2). PT11 transplants were characterized by GFAPimmunopositive long fibers that densely penetrated the transplants (Fig. 3). As astrocytes were also recognizable, the graft actually showed a mixed population of GFAP-immunopositive elements. Perivascular glia were also seen. The frequency of GFAP-positive elements was characteristically higher in the transplants than in the host cortex.

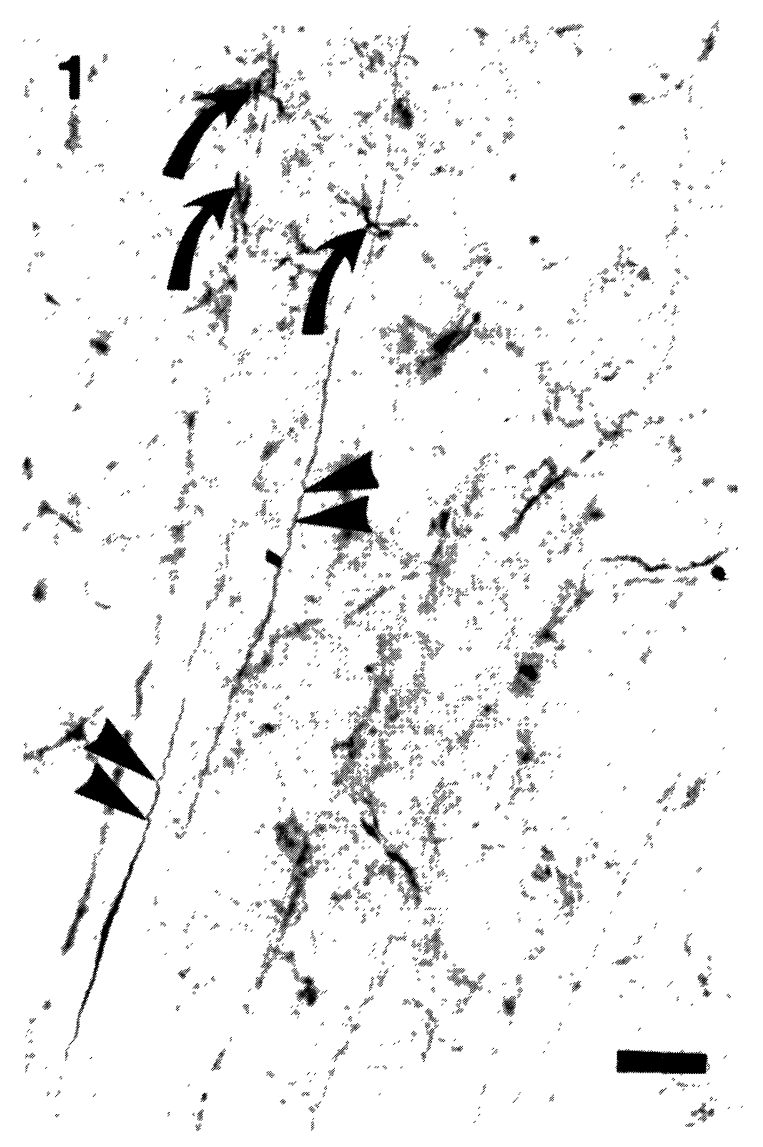

Fig. 1. Immunohistochemical labeling of radial fibers (double arrowheads) and astrocytes (curved arrows) in the in situ developing cortex at P10. Sections were serially incubated with mouse monoclonal antibody to GFAP, biotinylated rabbit anti-mouse $\mathrm{IgG}$, and then with streptavidin-biotinylated horseradish peroxidase complex. The enzyme was visualized by the peroxidase reaction. Bar: $50 \mu \mathrm{m}$. 


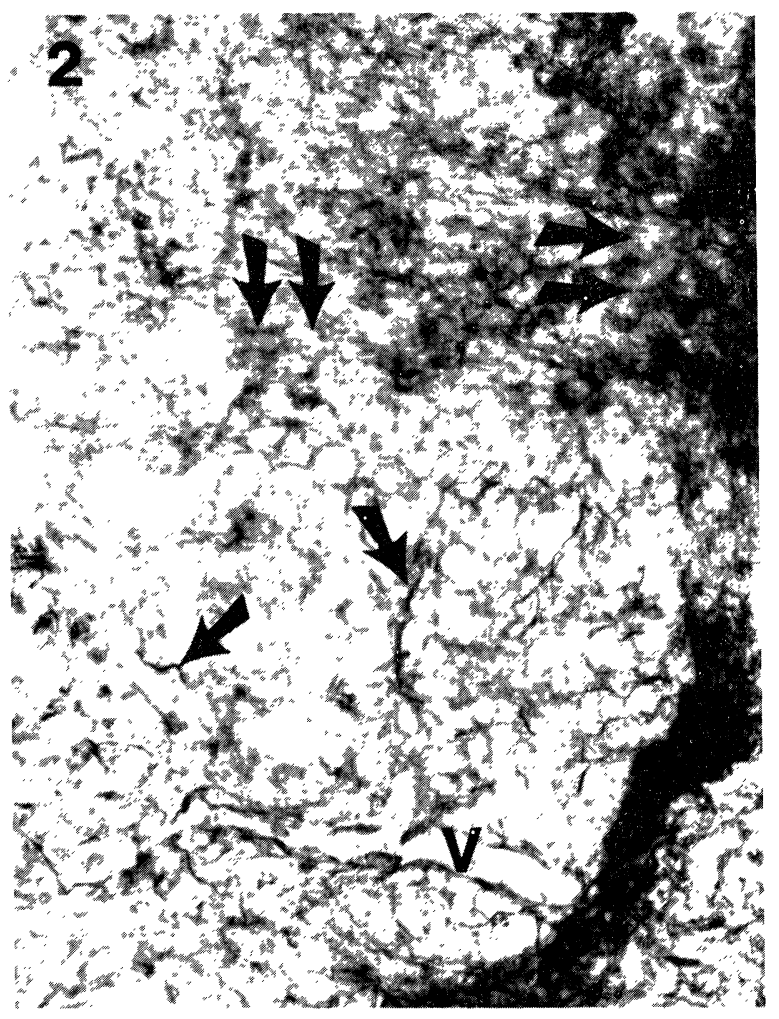

Fig. 2. GFAP-immunohistochemical staining of the grafted cortex at PT7 showing a few labeled structures (arrows) at the periphery of the transplant and beside the vessels (V). The postoperative hematoma persists (double arrows). See legend to Fig. 1 for method. Bar: $50 \mu \mathrm{m}$.

Around the graft, a reactive gliosis developed that seems to have been formed by the host glia. Figure 4 shows that immunostaining for vimentin labeled only a mesh of long fibers, which showed neither a parallel arrangement resembling the original radial glia nor an orientation toward the host/graft border. But nevertheless, we assume that the fibers corresponded to radial glia. The irregular arrangement may be due to a deformation of the telencephalic wall during transplantation and an irregular regrowth of the fibers. In the host cortex, only reactive astrocytes were vimentin-positive around the transplant.

In P14 transplants, mature GFAP-immunoreactive astrocytes had replaced the fibers. In some transplants (Fig. 5), however, a few long fibers persisted. Although the astrocytes were similar to those usually observed in the adult rat brain in situ, their distribution was denser. Vimentin immunostaining was also seen, but only in a subpopulation of astrocytes, and the staining was less intense than that in the GFAP-labeled elements. Transplants older than 14 days showed no significant difference from the 14-day transplants (not shown).

\section{DISCUSSION}

In the transplant experiments described here, transformation of vimentin-immunopositive radial glia into GFAP-positive astrocytes differed from the in situ development in the following details:

1. The transformation in the transplants occurred earlier than that in situ. Our observations on the in situ development are congruent with published data $/ 15,32,38 /$, suggesting that the transformation occurs mainly between the second and third postnatal weeks. In our transplants, however, such transformation occurred during the second postoperative week (corresponding to the first in-situ postnatal week). Indeed, the PT11 transplant (corresponding to P4 in situ) contained not only more astrocytes but also far more GFAP than the in situ P10 cortex.

2. In transplants, the duration of transformation was shorter (several days) than that in situ (two weeks). Such observations agree with the results of Bignami and Dahl /7/, which showed that a lesion in the neonatal brain evokes the appearance of GFAP without forming a permanent glial scar, as seen after stabbing in adults (reviewed in $/ 5,6 /$ ).

3. The presence of many GFAP-positive long fibers suggests that in transplants, the vimentinGFAP transition starts sooner than the transformation of radial glia into astrocytes. Unlike the in-situ process, the vimentinimmunopositivity in transplants does not decrease proportionally with the increase in GFAP immunopositivity.

The abundance of astroglia in the transplants relative to the number in the in-situ cortex has been noted by several authors $/ 9-11,16,23 /$. This phenomenon could be due to a greater survival ratio 

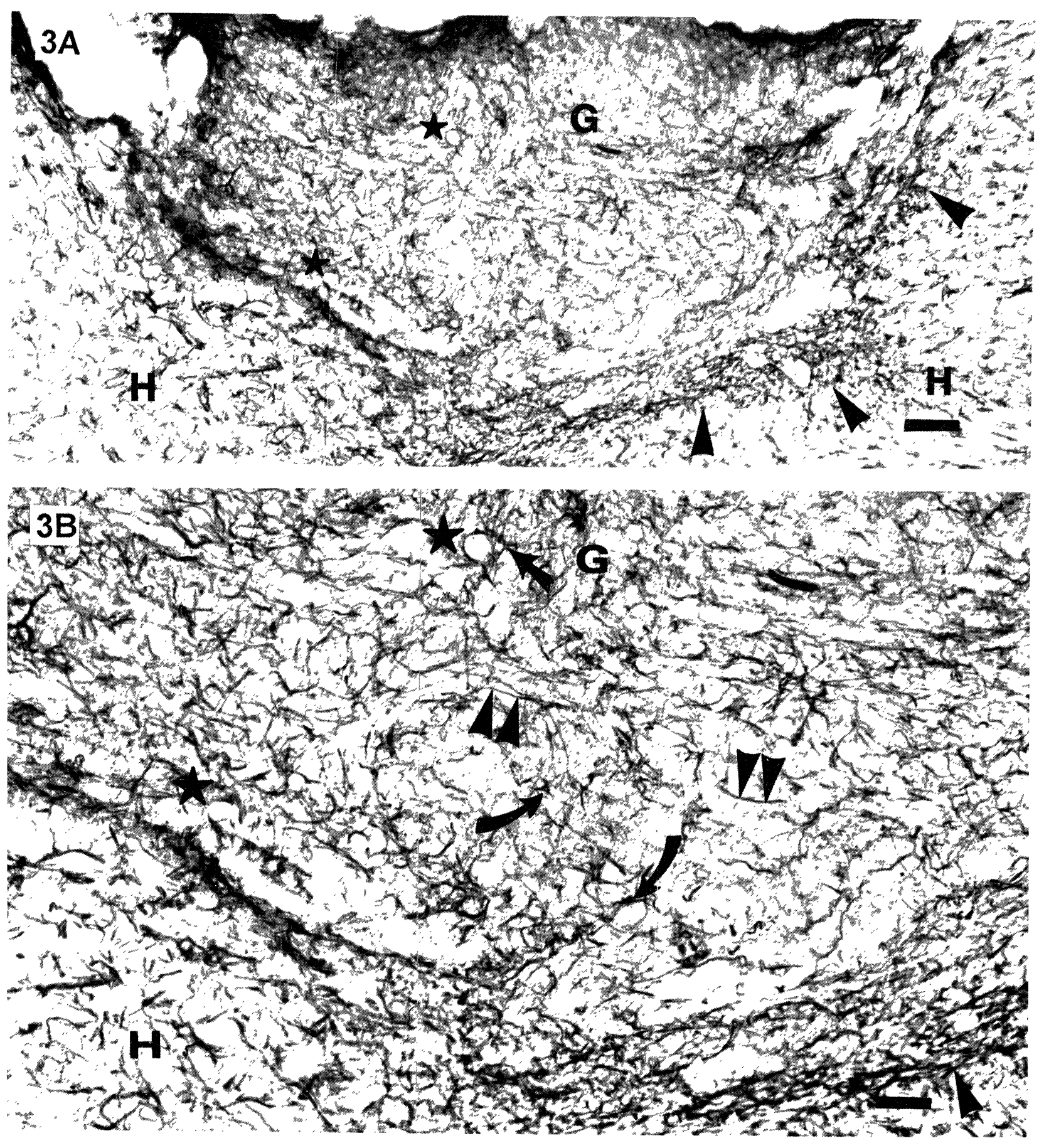

Fig. 3. GFAP-immunohistochemical staining of the grafted cortex at PT11 showing a mixed population of labeled long fibers (double arrowheads) and astrocytes (curved arrows). Perivascular glia are also present (straight arrow). GFAPimmunoreactivity is less abundant in the host cortex $(\mathbf{H})$ than in the graft $(\mathbf{G})$. Note that the reactive gliosis (arrowhead) affects mainly the host glia. Bar: $100 \mu \mathrm{m}$. (3B) Enlargement of Fig. 3A; Bar: $50 \mu \mathrm{m}$. Stars denote identical details. See legend to Fig. 1 for method. 

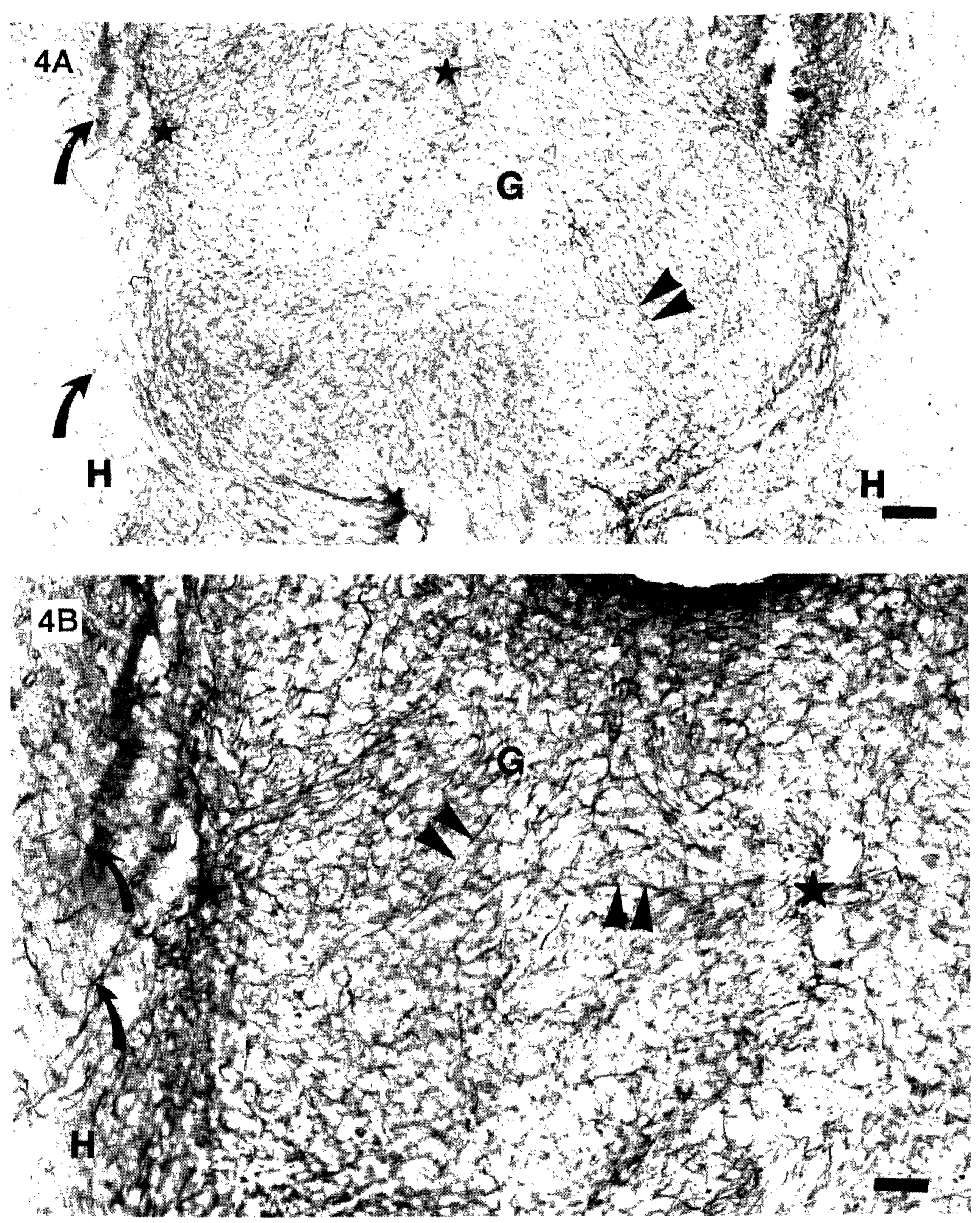

Fig. 4. (4A) Vimentin-immunohistochemical staining of the grafted cortex at PT11 showing labeled long fibers (double arrowheads) in the graft $(\mathbf{G})$, with no definitive arrangement. In the host $(\mathbf{H})$, only reactive astrocytes (curved arrow) around the transplant are labeled. Bar: $100 \mu \mathrm{m}$. (4B) Enlargement of Fig. 4A; Bar: $50 \mu \mathrm{m}$. The method was the same as described in the legend to Fig. 1, except that a monoclonal antibody to vimentin was the first antibody. 


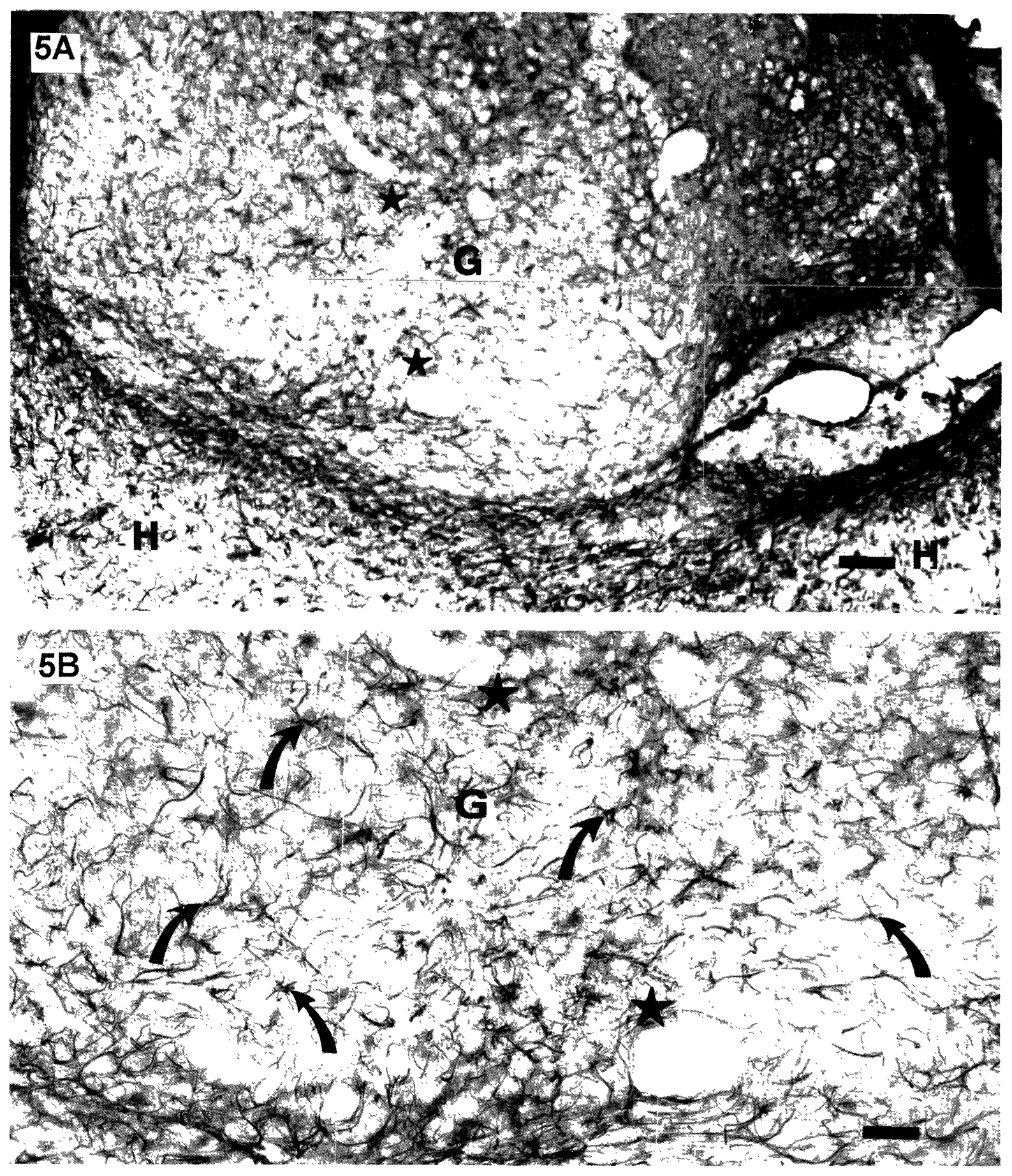

Fig. 5. (5A) GFAP-immunohistochemical staining of the grafted cortex at PT14 showing that astrocytes (curved arrows) are the predominant GFAP-labeled elements of the graft. $\mathbf{H}$ denotes the host cortex; the arrow denotes the perivascular glia in the graft. Bar: $100 \mu \mathrm{m}$. (5B) Enlargement of Fig. 5A; Bar: $50 \mu \mathrm{m}$. Stars mark identical details. See legend to Fig. 1 for method. 
in astroglia than in neurons, or it may correspond to a reactive gliosis after the lesion, by which the grafted tissue was separated from the donor brain $110,11,16 /$. That immature astroglia do not form a permanent glial scar has been suggested; in fact, the astroglia diminish the effect of lesions in the adult brain $/ 4,7,32,38,40 /$. Our observation that the reactive gliosis around the transplant appeared to be generated by the host rather than by the grafted glia (for similar observations) agrees with this opinion. The presence of vimentin immunopositivity in reactive gliosis (shown in Figs. 4A and 4B) and in the astrocytes of transplants has been previously reported $/ 19,27,37 /$. In the latter case, the presence of vimentin can be either a sign of a reactive characteristic or a feature that has persisted since the immature stage of astrocytes in the transplant.

In conclusion, after transplantation, astroglia undergo an accelerated histogenesis that is likely to be provoked by the effects of lesions in both the donor and the host tissues

\section{ACKNOWLEDGMENTS}

The authors thank Ms. Z. Vidra for supplying time-mated pregnant animals, Ms. M. Tóth for the pre- and post-operative treatment of the animals, and Mr. J. Kiss for the photographic work.

\section{REFERENCES}

1. Abner ER, Bartlett PP, Raff MC. Astrocytes, ependymal cells, and oligodendrocytes develop on schedule in dissociated cell cultures of embryonic rat brain. Dev Biol 1981; 83: 301-310.

2. Albarez-Buylla A, Buskrk DR, Nottebohm F. Monoclonal antibody reveals radial glia in adult avian brain. J Comp Neurol 1987; 264: 159-170.

3. Antanitus DS, Choi BH, Lapham LW. The demonstration of glial fibrillary acidic protein in the cerebrum of the human fetus by indirect immunofluorescence. Brain Res 1976; 103: 613-616.

4. Barrett CP, Donati EJ, Guth L. Differences between adult and neonatal rats in their astroglial response to spinal injury. Exp Neurol 1984; 84: 374-385.

5. Berry M, Maxwell WI, Logan A, Mathewson A, McConnell P, Ashhurst DE, Thomas GH. Deposition of scar tissue in the central nervous system. Acta Neurochir (Suppl) 1983; 32: 31-53.
6. Bignami A, Dahl D, Rueger DC. Glial fibrillary acidic protein (GFAP) in normal cells and in pathological conditions. Adv Cell Neurobiol 1980; 1: 285-310.

7. Bignami A, Dahl D. Astrocyte-specific protein and radial glia in the cerebral cortex of newborn rat. Nature $1974 ;$ 252: 55-56.

8. Björkland A. Neural transplantation-an experimental tool with clinical possibilities TINS 1991; 14: 319322.

9. Björkland H, Bickford P, Dahl D, Hoffer B, Olson L. Intracranial cerebral grafts: Intermediate filament immunohistochemistry and electrophysiology. Exp Brain Res 1984; 55: 372-385.

10. Björkland H, Dahl D. Glial disturbances in isolated neocortex: Evidence from immunohistochemistry of intraocular grafts. Dev Neurosci 1982; 5: 424-435.

11. Björkland H, Dahl D. Haglid K, Rosengren L, Olson L. Astrocytic development in fetal parietal cortex grafted to cerebral and cerebellar cortex of immature rats. Dev Brain Res 1983; 9: 171-180.

12. Björkland H, Dahl D, Olson L. Morphometry of GFAand vimentin-positive astrocytes in grafted and lesioned cortex cerebri. Int J Dev Neurosci 1984; 2: 181-192.

13. Blakemore WF, Franklin RJM. Transplantation of glial cells into the CNS. TINS 1991; 14:323-327.

14. Cassel JC, Kelche C, Majchrzak M, Will BE. Factors influencing structure and function of intracerebral grafts in the mammalian brain: A review. Res Neurol Neurosci 1992; 4: 65-96.

15. Choi BH. Glial fibrillary acidic protein in radial glia of early human fetal cerebrum: A light and electron microscopic immunoperoxidase study. J Neuropathol Exp Neurol 1986; 45: 408-418.

16. Connor JR, Bernstein JJ. Astrocytes in rat fetal cerebral cortical homografts following implantation into adult rat spinal cord. Brain Res 1987; 409: 62-70.

17. Dahl $D$. The vimentin-GFA transition in rat neuroglia cytoskeleton occurs at the time of myelination. J Neurosci Res 1981; 6: 741-748.

18. Dahl D, Rueger DC, Bignami A. Vimentin, the 57,000 molecular weight protein in fibroblast filaments in the major cytoskeletal protein in immature glia. Eur J Cell Biol 1981; 24: 191-196.

19. Dahl D, Strocchi $P$, Bignami A. Vimentin in the central nervous system. A study of the mesenchymaltype intermediate filament protein in Wallerian degeneration and in postnatal rat development by twodimensional gel electrophoresis. Differentiation 1982; 22: $185-190$.

20. Das GD, Ross DT. Neural transplantation: Autoradiographic analysis of histogenesis in neocortical transplants. Int J Dev Neurosci 1986; 4: 69-79.

21. Eng LF, Vanderhagen VJ, Bignami A, Gerstl B. An acidic protein isolated from fibrosus astrocytes. Brain Res 1971; 28: 351-354. 
22. Engel AK, Müller CM. Postnatal development of vimentin-immunopositive radial glial cells in the primary visual cortex of the cat. J Neurocytol 1989; 18: 437-450.

23. Eriksdotter Nilsson M, Björkland H, Dahl D, Olson L. Growth and development of intraocular fetal cortex cerebri grafts in rats of different ages. Brain Res 1986; 393: 75-84.

24. Feodoroff S. Prenatal ontogenesis of astrocytes. In: Feodoroff S, Vernadakis A, eds, Astrocytes Vol 1. New York: Academic Press, 1986; 35-74.

25. Fisher LJ, Gage FH. Grafting in the mammalian central nervous system. Physiol Rev 1993; 73: 583.

26. Kálmán M. Vimentin persists in the mature glia of fish brain. Neurobiol 1993; 1: 47-54.

27. Janeczko $K$. Coexpression of GFAP and vimentin in astrocytes proliferating in response to injury in the mouse cerebral hemisphere. A combined autoradiographic and double immunocytochemical study. Int J Dev Neurosci 1993; 11: 139-147.

28. Levitt P, Rakic P. Immunoperoxidase localization of glial fibrillary acidic protein in radial glial cells and astrocytes of the developing Rhesus monkey brain. J Comp Neurol 1980; 193: 815-840.

29. Lindvall O. Prospects of transplantation in human neurodegenerative diseases. TINS 1991; 14: 376-384.

30. McDermott KW, Lantos PL. The distribution of glial fibrillary acidic protein and vimentin in postnatal marmorset (Callithrix jacculus) brain. Dev Brain Res 1989; 45: 169-177.

31. Misson JP, Takahashi R, Verne S, Caviness JR. Ontogeny of radial and other astroglial cells in murine cerebral cortex. Glia 1991: 4: 138-148.

32. Müller CM, Best J. Ocular dominance plasticity in adult cat visual cortex after transplantation of cultured astrocytes. Nature 1989; 342: 427-430.

33. Onteniente B, Kimura $H$, Maeda $T$. Comparative study of the glial fibrillary acidic protein in vertebrates by PAP immunohistochemistry. J Comp Neurol 1983; 215: 427-436.

34. Pixley SR, de Vellis J. Transition between immature radial glia and the mature astrocytes studied with monoclonal antibody to vimentin. Dev Brain Res 1984; 15: 201-209.
35. Rakic P. Neuronal-glial interaction during development. TINS 1981; 4: 184-187.

36. Schmechel DE, Rakic P. A Golgi study of radial glial cells in developing monkey telencephalon: Morphogenesis and transformation into astrocytes. Anat Embryol 1979; 156: 115-152.

37. Smith LM, Ebner FF. The differentiation of nonneuronal elements in neocortical transplants. In: Björkland A, Stenevi U, eds, Transplantation in the mammalian CNS. Amsterdam: Elsevier, 1985; 81-101.

38. Smith GM, Miller RH, Silver J. Astrocyte transplantation induces callosal regeneration in postnatal acallosal mice. Ann NY Acad Sci 1987; 495: 185-206.

39. Smith GM, Miller RH, Silver J. Changing role of forebrain astrocytes during development, regenerative failure, and induced regeneration upon transplantation. J Comp Neurol 1986; 251: 23-43.

40. Stichel CC, Müller CM, Zilles K. Distribution of glial fibrillary acidic protein and vimentin immunoreactivity during rat visual cortex development. J Neurocytol 1991; 20: 97-108.

41. Sturrock RR. Postnatal ontogenesis of astrocytes. In: Feodoroff S, Vernadakis A, eds, Astrocytes Vol 1. New York: Academic Press, 1986; 75-102.

42. Voight T. Development of glial cells in the cerebral walls of ferrets: Direct tracing of their transformation from radial glia into astrocytes. J Comp Neurol 1989; 289: 74-88

43. Williams BP, Abney ER, Raff MC. Macroglial cell development in embryonic rat brain: Studies using monoclonal antibodies, fluorescence-activated cell sorting, and cell culture. Dev Biol 1985; 112: 126-134.

44. Yanes C, Monzon-Mayer M, Ghandour MS, deBarry J, Gombos G. Radial glia and astrocytes in the adult and developing telencephalon of the lizard Galldotia galloti as revealed by immunohistochemistry with antiGFAP and anti-vimentin antibodies. J Comp Neurol 1990; 295: 559-568.

45. Zhou FC, Buchwald N, Hull C, Towle A. Neuronal and glial elements of fetal neostriatal grafts in the adult neostriatum. Neuroscience 1989; 30: 19-31. 

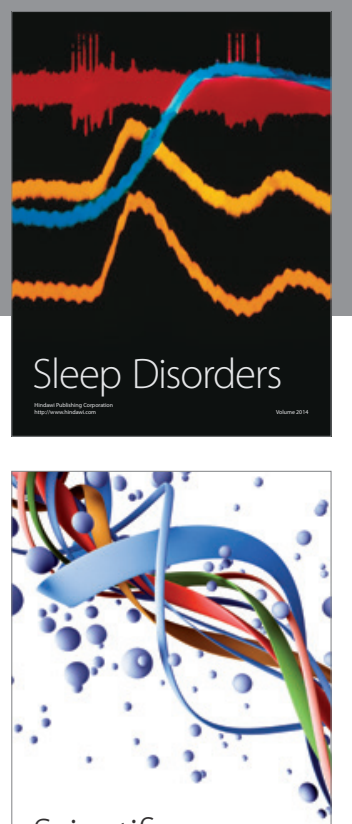

Scientifica
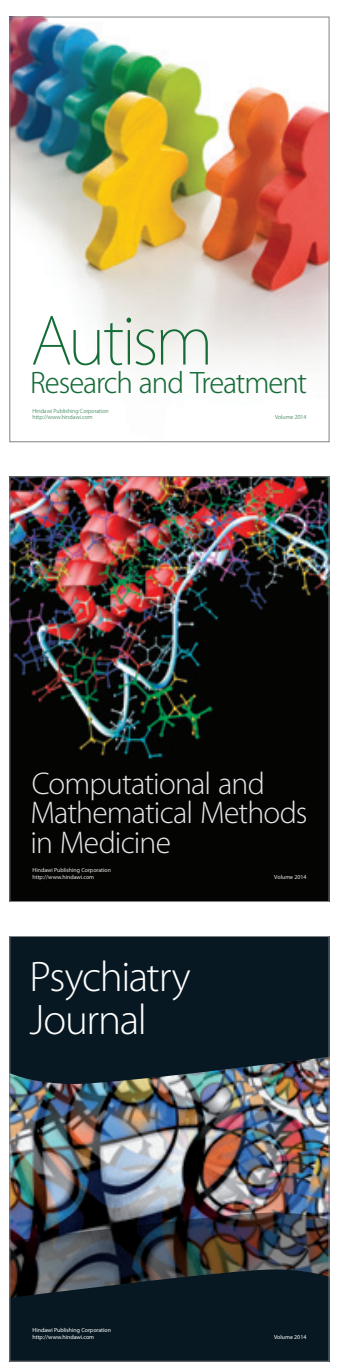
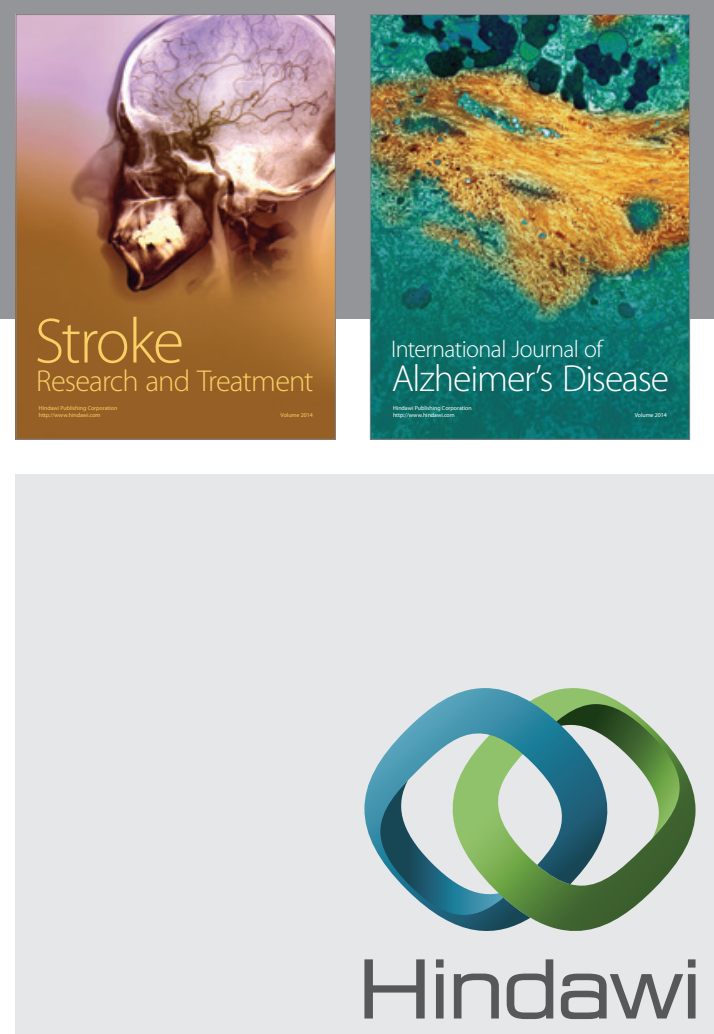

Submit your manuscripts at

http://www.hindawi.com
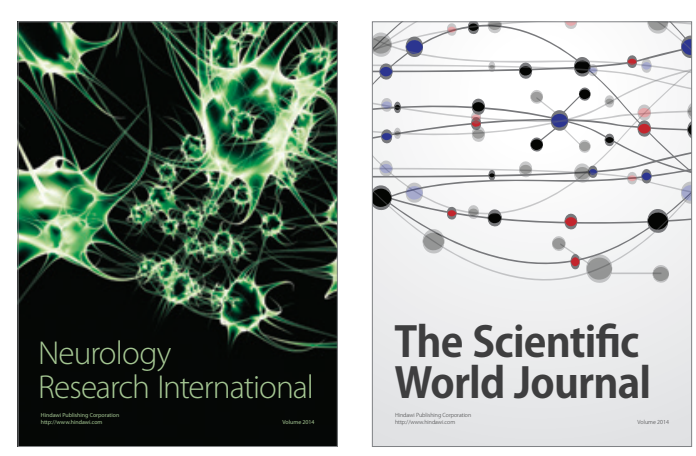

The Scientific World Journal

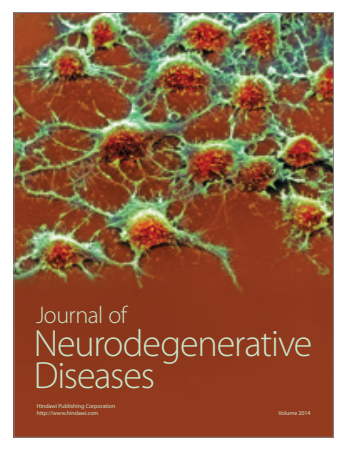

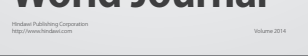

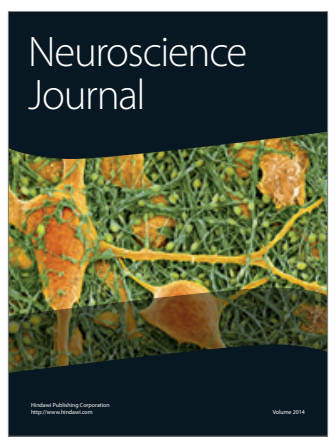

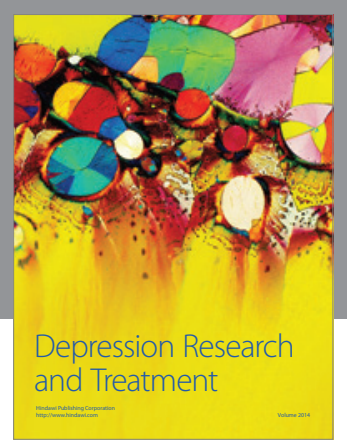
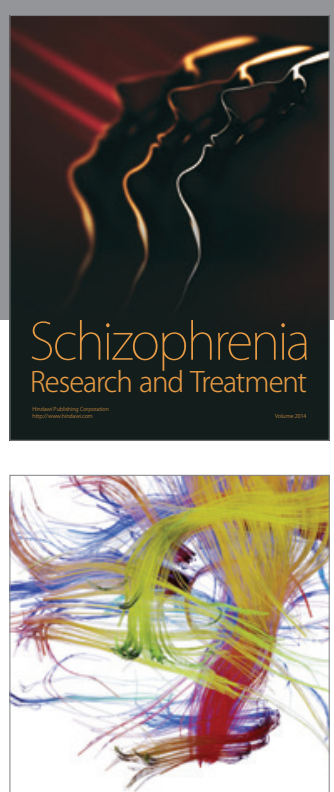

Brain Science

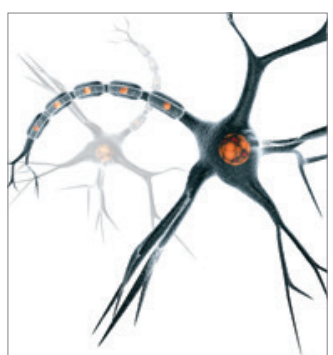

Neural Plasticity
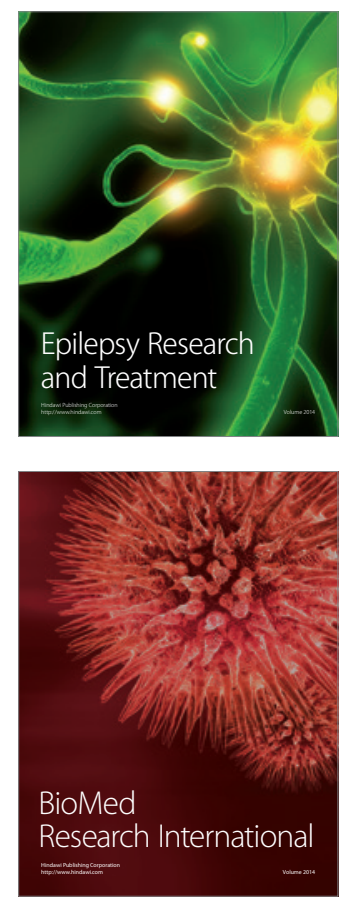

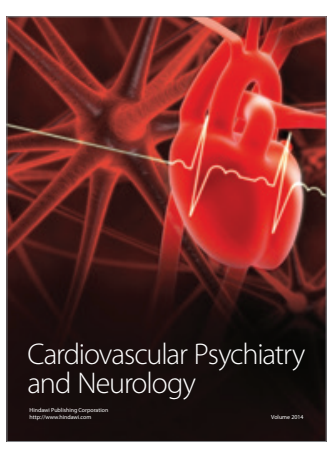

Parkinson's

Disease
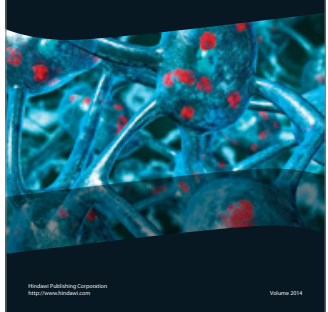